\title{
Development efficiency Evaluation of Power Project Based on Total Social Cost and Super-efficiency DEA
}

\author{
Jinchao $\mathrm{Li}^{\mathrm{a}}{ }^{\text {* }}$, Yuwei Xiang ${ }^{\mathrm{b}}$ \\ School of Economics and Management, North China Electric Power University, Beijing 102206, \\ China \\ aemail: lijc78@163.com, bemail:xywedu@163.com, ${ }^{*}$ corresponding author
}

\author{
Keywords: SE-DEA, Power Projects, Total Social Cost
}

\begin{abstract}
In order to evaluate the development efficiency of different types of power projects, combined with the characters of power projects, the evaluation index system of power generation efficiency decided by input indicators and output indicators. The model based on super-efficiency data envelopment analysis (SE-DEA) is proposed, the method of quantitative calculation, the comprehensive efficiency of different types of power projects is obtained by the method of quantitative calculation. All aspects of society considered, on the current stage of our country, natural gas cogeneration is a kind of environment-friendly power generation projects, and it should be supported.
\end{abstract}

\section{Introduction}

With the rapid development of social economic power generation shows a trend of diversification. In the composition of China's power generation, power plant accounts for the main position, power generation depends mainly on coal, oil and natural gas. But coal is a kind of non-renewable resources. Its reserves are accelerating to reduce, China's oil and natural gas reserves are poor. So the use of other resources should meet the demand of electricity generation, including clean solar power generation, energy-saving wind power generation and efficient nuclear power generation. In such a diverse form of power generation, power generation efficiency has become the focus of the power industry. Teng [1] used DEA to analyze the data of coal-based power plants in China in 1991, he found that low efficiency was mainly caused by the excessive use of fuels and the remaining $5 \%$ was caused by excessive labor. The power consumption standard coal consumption decreased from $370 \mathrm{~g}(\mathrm{kWh})-1$ in 2005 to $319 \mathrm{~g}$ (kWh)-1 in 2014, and the power consumption rate of thermal power plants decreased from 6.8\% in 2005 to 5.84\% in 2014[2]. Method that increasing the output of coal to ensure energy supply will be subject to resources, environment, transportation and other factors. It is difficult to continue. Nuclear power is currently the world's only mature technology. This safe and clean energy sources can reduce greenhouse gas emissions. Therefore, the development of nuclear power is an important strategic choice for Chinese energy[3].Wang[4] found nuclear power technology is advanced, and it can be used for a long time, under the same scale, nuclear power generation capacity is much higher than thermal power. However, wind power is already competitive with nuclear power. Assuming wind conditions are good, equipment utilization is $35 \%$, power generation cost is 7.95 Yen / $\mathrm{kWh}$ was found by Luo[5]. Among various renewable energy sources, wind energy is one of the fastest-growing energy sources, worldwide has a good prospect of development and utilization[6].CHP (Combined Heating \& Power/ District Heating \& Cooling) is a kind of important energy efficiency and environmental protection technology[7]. Ji [8] revealed natural gas cogeneration has a very high external environmental value, natural gas-fired cogeneration project is playing an important role in environment improvement, ecosystem facilitation and clean energy development. Qian[9] found solar energy is considered to be "inexhaustible", but the current application of photovoltaic power generation system is still limited, the average cost of photovoltaic energy is between 35 to 50 cents / kWh. Comparatively speaking, other energy sources are much cheaper (coal and natural gas costs 5-6 cents / kWh). 


\section{Evaluation index system}

This paper focuses on the input-output efficiency of power generation project, not to study the economics of the entire energy chain, the main consideration in external costs is the environmental costs of pollutant emissions. The internal cost includes two parts, namely the construction investment cost of the power project and the total cost of electricity and heat production in the whole operation period. Fig 4 presents the index system of power generation project development efficiency.

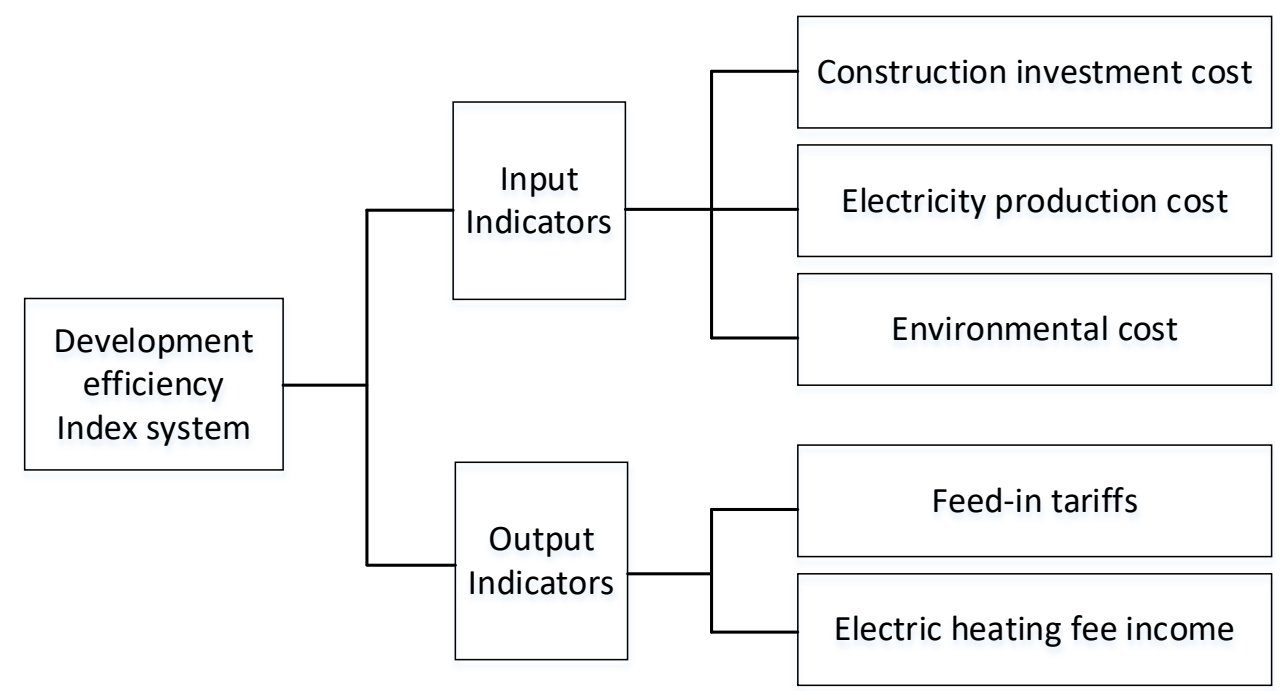

Figure.1. The index system of power generation project development efficiency

Input indicators. Construction Investment Cost. According to the estimation method, construction investment of electric power construction project consists of main and auxiliary production project cost, single project cost, preparation of annual price difference, other expenses, special expenses and dynamic expenses. Dynamic cost generally refers to the construction period of loan interest. Among them, the project cost can be divided into construction costs, installation costs and equipment purchase costs, including the main and auxiliary production engineering costs and individual project costs.

Electricity Production Cost. Electricity and thermal power generation costs include the costs of fuel, water, materials, wages and welfare, depreciation, amortization, repairs, sewage charges, other charges and insurance premiums for different types of power generation The proportion is different.

Environmental Costs. Environment as part of the cost of electricity production process is the impact on the external environment, but at the same time, no one to bear this part of the cost, this part of the natural environment or biological damage, but can not be reflected in the market price, which Part of the cost is called the environmental cost. Various power generation types Environmental cost $=$ Annual electricity generation $\times$ Location area Unit electricity generation Environmental cost $\times$ Project operation period.

Output Indicators. Feed-in Tariffs. Total feed-in tariffs $=$ Annual feed-in tariffs $\times$ Project Operation Period=Total installed capacity $\times$ annual power generation utilization hours $\times$ integrated plant power consumption $\times$ project operation period.

Electric Heating Fee Income. Electric heating fee income=annual heat supply $\times$ heating unit price $\times$ project operation period

\section{Super - efficiency DEA Model}

Efficiency Calculation Model of Generation Project Based on Super - efficiency DEA Model. The DEA model divides the decision-making units into two classes, namely, effective and ineffective, and cannot make further evaluation and comparison for multiple simultaneous decision-making units. To remedy this shortcoming, Andersen and Petersen (1993) proposed a DEA "super-efficiency" (Super-Efficiency) model, so that effective decision-making units can also be 
compared between the level of efficiency. The basic idea of this model is: in the evaluation of decision-making unit, the decision-making unit itself excluded from the decision-making unit of the collection. The super-efficiency model is as follows.

$$
\begin{array}{ll}
\min & \theta \\
\text { s.t. } & \sum_{\substack{j=1 \\
j \neq 0}}^{n} x_{i j} \lambda_{j}+S_{i}^{-}=\theta x_{0}, i=1, \cdots, m \\
& \sum_{\substack{j=1 \\
j \neq 0}}^{n} y_{r j} \lambda_{j}-S_{r}^{+}=y_{0}, r=1, \cdots, s \\
& \lambda_{j} \geq 0, j=1,2, \cdots, n, \theta \in E_{1}^{+}, S^{-} \geq 0
\end{array}
$$

Where $\theta$ is the efficiency value of the decision-making unit; evaluation index system consists of $m$ inputs and $s$ output indicators. Let $x_{i j}$ be the input of the $j$ th decision unit to the $i$ type input, $y_{r j}$ be the output of the $j$ th decision unit to the $r$ type output, and $S_{r}^{+}$and $S_{i}^{-}$be the relaxation variable respectively. $\lambda_{j} S_{i}^{-} S_{r}^{+}, \theta$ for the parameters to be estimated.

\section{Empirical research}

Raw Data. In this paper, five different representative power generation devices are used to represent the data of cogeneration, nuclear power, wind power, photovoltaic, heat-engine plant (DN1, DN2, DN3, DN4, DN5). Table 1 reports the values of efficiency input indexes. Table 2 reports the values of efficiency output indexes.

Table.1. Values of efficiency input indexes

\begin{tabular}{cccccc}
\hline \multicolumn{7}{c}{ DN1 } & DN2 & DN3 & DN4 & DN5 \\
\hline $\mathrm{I}_{1}$ & 235448 & 3176941 & 129795 & 19793 & 450686 \\
$\mathrm{I}_{2}$ & 3404399 & 4242776 & 95034 & 12149 & 1042110 \\
$\mathrm{I}_{3}$ & 389609 & 394022 & 185 & 19 & 1384294 \\
\hline \multicolumn{5}{c}{ Table.2. Values of efficiency output indexes } \\
\hline $\mathrm{O}_{1}$ & DN1 & DN2 & DN3 & DN4 & DN5 \\
$\mathrm{O}_{2}$ & 5940000 & 52500000 & 1234752 & 84381 & 18612000 \\
\hline
\end{tabular}

Calculation Results. According to the data of input and output indexes data of each type of power generation project, the linear programming solution of the super-efficiency model is obtained by using the software ems1.30. Table 3 reports the Super - efficiency model results.

Table.3. Super - efficiency model results table

\begin{tabular}{cccccc}
\hline & DN1 & DN2 & DN3 & DN4 & DN5 \\
\hline Construction investment cost & 0 & 0.88 & 0.97 & 0 & 0 \\
Electricity production cost & 0 & 0 & 0 & 0 & 1 \\
Environmental costs & 1 & 0.12 & 0.03 & 1 & 0 \\
feed-in tariffs & 0 & 1.53 & 2.21 & 0.67 & 1.37 \\
Electric heating fee income & 4.39 & 0 & 0 & 0 & 2.29 \\
Efficiency value & 4.3862 & 1.5326 & 2.2074 & 0.6654 & 3.6655 \\
sort & 1 & 4 & 3 & 5 & 2 \\
\hline
\end{tabular}

The results showed that this evaluation method can evaluate the different types of power generation projects from the perspective of the whole society, and can provide guidance and suggestions for the future social production. Such as the DN1 plant, which cogeneration efficiency value is $438.62 \%$, is much higher than other industries, because the project is technologically advanced, environmentally friendly, and can meet the heating needs of residents. But, the DN3 plant as the representative of the PV project, which efficiency value is the lowest for the following 
reasons. First, the EU investigated China's photovoltaic products, "double reverse" investigation is China and the EU so far the largest trade disputes, also the world's largest trade dispute involving an estimated amount of 200 billion RMB. China's photovoltaic industry suffered this robbery, the competitive advantage has ceased to exist; Second, domestic silicon cell efficiency is between 10 and 13\%, efficiency is too low; Third, the cost of photovoltaic power generation is still 1.4-2 RMB / $\mathrm{kWh}$, the price in the market is not competitive. Efficiency ranked second is the coal power plant. The other three plants, DN5 efficiency value is in second place, due to the country to improve the access value of the relevant projects, and the project uses the relevant advanced technology; DN3 represents wind power, wind power is typical Environment-friendly projects, and the domestic technology matures have a good development prospects; DN2 is representative of nuclear power, nuclear power construction costs and environmental costs are too high, resulting in its overall efficiency is low.

\section{Conclusion}

Based on the social point of view, this paper establishes the evaluation index system for different types of power generation, and uses the super-efficiency DEA model and EMS software to conclude that the environmental cost of natural gas cogeneration project is the lowest among the fossil energy generation types. Natural gas cogeneration project in all types of power generation among the input and output efficiency is the highest. Similarly, its contribution to social heating is great. The research of this paper provides important reference for the development of the natural gas cogeneration project, and also provides the decision-making basis for the relevant units of energy planning, power companies, heat companies, natural gas operators and other related parties.

\section{Acknowledgement}

This work has been supported by "Ministry of Education, Humanities and Social Science Fund, Nos. 15YJC630058”, "Beijing Higher Education Young Elite Teacher Project Nos. YETP0709”, “the Science and Technology Project of SGCC.”

\section{References}

[1] Teng., et al., Performance Analysis of China 's Electric Power. The number of economic and technological economic research ,2003.(6): p.127-130 .

[2] China Electricity Council. Annual Report on China's Power Sector 2015 [M]. Beijing: China Market Publishing House, 2015.

[3] WANG Xinxin,. China's Nuclear Power Development in the New Period Study on Present Situation and Countermeasures. Energy conservation technology,2010.(1):p.60-64.

[4] WANG Dong,A Comparative Study on Technical Efficiency of Nuclear Power and Thermal Power in China.Sci-Technology and Management.2005.32(4):p.1-9.

[5] LUO Chengxian. Wind Power Generation Today in the World and Prospect Forecast. Sino-global energy.2012.(3):p.24-31.

[6] Liu., et al., Present Situation and Development Trend of Modern Large - scale Wind Turbine. China mechanical engineering.2013.(1):p.125-135.

[7] US EPA CHP Partnership and Asia Pacific Partnership (APP) on Clean Development and Climate. Facilitating Deployment of Highly Efficient Combined Heat and Power Applications in China[R].2008.3.

[8] Zhang., et al., Total Social Cost-Based Economic Evaluation Research on Natural Gas Cogeneration Project.2016. 
[9] QIAN Bozhang. Cost and Prospect on Solar Energy Photovoltaic(PV) Power Generating. China Environmental Protection Industry.2009.(4): p.24-28. 